\title{
PERCEPÇÃO ESPACIAL ESTUDANTIL EM PÁTIOS DE ESCOLA PÚBLICA DE ENSINO EM PALMITINHO, RS, BRASIL
}

\author{
RECH, Gracielle Rodrigues da Fonseca (1); \\ VALLE, Ângela do (2); \\ LERMEN, Bruna Cristina (3)
}

(1) Unidade Central De Educação Faem Faculdade, Mestre em Arquitetura e Urbanismo

e-mail: graciellerfrech@hotmail.com

(2) Universidade Federal de Santa Catarina, Doutora em Engenharia Civil

e-mail: angela.valle@ufsc.br

(3) Universidade Regional Integrada do Alto Uruguai e das Missões, Acadêmica de Graduação

e-mail: brunalermen@hotmail.com

\begin{abstract}
RESUMO
Partindo do tema arquitetura de pátios escolares, a pesquisa teve por objetivo analisar o pátio de escolas públicas de ensino fundamental, segundo o ponto de vista do estudante. $\mathrm{O}$ artigo apresenta a avaliação realizada em uma instituição pública de ensino localizada no município de Palmitinho - Rio Grande do Sul, com ênfase nos instrumentos de análise aplicados: mapa cognitivo e poema dos desejos. O propósito da investigação é compreender as relações de uso e apropriação desses espaços, averiguando a qualidade das áreas livres e ambiente construído. A participação dos usuários mostrou-se fundamental para a obtenção de espaços de qualidade.
\end{abstract}

Palavras chave: pátio escolar; percepção espacial; usuários.

\begin{abstract}
Starting from the theme of schoolyard architecture, the research aimed to analyze the courtyard of public elementary schools, according to the point of view of the students. The article presents the evaluation carried out at a public educational institution located in the city of Palmitinho, Rio Grande do Sul, with emphasis on the instruments of analysis applied: cognitive map and poem of desires. The purpose of the investigation is to understand the relations of use and appropriation of these spaces, ascertaining the quality of the free areas and built environment. The participation of the users was fundamental for the obtaining of quality spaces.
\end{abstract}

Keywords: school yard; spatial perception; users.

\section{INTRODUÇÃO}

A educação de uma criança se inicia no convívio familiar sendo, posteriormente, dividida com a escola que participa cada vez mais precocemente do processo educacional. Neste contexto, o pátio escolar constitui um ambiente fundamental para o desenvolvimento $\mathrm{e}$ 


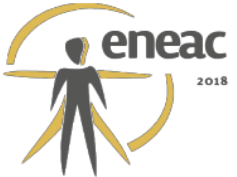

socialização das crianças, ao permitir interação entre elas e todos que fazem parte das escolas (NORBERG-SCHULZ, 1981).

Do ponto de vista da Arquitetura, um bom espaço físico escolar, expressado pelos aspectos perceptivos - conceituais, formais e estéticos - é aquele reconhecido pela representatividade e que influência o seu entorno próximo, afirma Kowaltowski (2011).

A harmonia entre o usuário e o ambiente é uma questão que deve ser relacionada, pois deve haver uma interação entre espaço físico, atividades pedagógicas e comportamento humano. Assim, o enfoque no estudo do pátio escolar pode ser justificado pelo mesmo configurar-se como elemento importante na formação do ser humano.

Embora exerça uma importante função, que influencia todo o processo de desenvolvimento infantil, há poucas reflexões sobre a concepção de pátios escolares no Brasil, segundo Azevedo; Rheingantz; e Tângari (2011). "É comum, no processo projetual que a área destinada ao pátio seja tratada e concebida como mero espaço residual - "sobra" do terreno -, inadequado para as atividades de recreação, exploração, convívio e socialização das crianças".

Ainda, o estudo acerca dos pátios de escolas e o esforço para melhorar a qualidade desses ambientes têm se tornado cada vez mais importante devido à escassez de espaços livres nas cidades. Os poucos espaços livres de construção existentes nas escolas, de forma geral, não são utilizados com frequência, em virtude da falta de manutenção e de adequação às atividades que neles podem ser desenvolvidas. A resultante desse processo de crescimento urbano é a elevação da importância do pátio escolar no sistema de espaços não construídos das cidades.

A partir destas abordagens, o estudo realizado tem como objetivo analisar a organização dos pátios de uma escola de ensino fundamental localizada no município de Palmitinho, Rio Grande do Sul-Brasil, com ênfase no uso e na apropriação pelos usuários. Procurou-se investigar e observar quais aspectos dos pátios escolares interferem na apropriação espacial por parte dos estudantes. O foco da pesquisa está na observação e compreensão da relação existente entre a percepção e o uso por parte do usuário, bem como das características e configurações do ambiente, aplicando técnicas e instrumentos de avaliação pós-ocupação para o desenvolvimento dessas análises.

Segundo Rheingantz et al. (2009), a Avaliação Pós-Ocupação (APO) é um processo interativo, sistematizado e rigoroso de avaliação do desempenho do ambiente construído, passado algum tempo de sua construção e ocupação. Os conceitos e técnicas adotados fazem parte de um escopo para se absorver e compreender como a comunidade e usuários percebem, observam e interagem com o ambiente. Conforme Tavares Filho (2005), os resultados da APO podem servir de subsídios para novos projetos similares, com a intenção de não apresentarem os mesmos problemas já constatados, bem como para correção de projetos existentes. Assim, os procedimentos de análise do ambiente dos pátios escolares se dividiram em dois tipos:

(a) análise objetiva (aspectos físicos e morfológicos), onde se realizou o mapeamento dos locais e levantamento de dados, com o objetivo de analisar os espaços livres existentes nas edificações elencadas. Ressalta-se que, devido aos projetos arquitetônicos não estarem disponíveis, tal procedimento foi realizado in loco.

(b) análise subjetiva (aspectos subjetivos, simbólicos e culturais), na qual se analisa como se dá a ocupação das áreas livres, as atividades realizadas e o comportamento dos usuários, de acordo com suas vivências e experiências, havendo uma interação direta ou indireta entre o pesquisador e os usuários.

Tais análises são complementares entre si, e auxiliam na obtenção dos objetivos da pesquisa. Ressalta-se que o artigo desenvolve-se a partir da análise subjetiva realizada de 


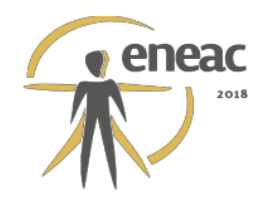

modo a responder às seguintes inquietações motivadoras: como o estudante vê e sente o espaço? Quais anseios os usuários apresentam sobre o mesmo?

Desta forma, o artigo irá focalizar a construção e aplicação de dois instrumentos pertencentes ao grupo de análise subjetiva - mapa cognitivo e poema dos desejos, devido à relação direta existente entre usuários e pesquisador nessas técnicas. No decorrer da transcrição do artigo, serão apresentadas as etapas desenvolvidas durante a realização da análise subjetiva, dando ênfase à metodologia aplicada para a realização de tal estudo, bem como a análise e síntese dos resultados obtidos a partir do estudo de caso realizado no Instituto Estadual de Educação 22 de Maio, localizado na cidade de Palmitinho, região noroeste do Rio Grande do Sul.

Assim, são relatados os resultados parciais da pesquisa desenvolvida sobre apropriação espacial em pátios escolares, de forma a identificar os aspectos que podem interferir no processo de apropriação destes espaços por parte das crianças usuárias.

\section{FUNDAMENTAÇÃO TEÓRICA}

A etimologia da palavra pátio - do latim: Pateo - define como: estar aberto; exposto; estender-se; abrir-se; estar descoberto; manifestar-se; ser evidente. As palavras sugerem o conceito de relacionamento com o ambiente físico, a cultura, as pessoas, etc.

Apesar da importância do pátio em termos de dimensão $\left(\mathrm{m}^{2}\right)$ e como local de atividade e interação social, na maioria das escolas brasileiras este espaço é omitido. Assim, os pátios escolares ainda são vistos apenas como um lugar onde as crianças podem ficar quando não estão desenvolvendo suas atividades em sala de aula, e por isso não seguem um projeto definido (FEDRIZZI, 2002).

O ministério da Educação não estabelece critérios específicos para a construção dos pátios das escolas. Sua única recomendação é que a área livre da escola deva ocupar pelo menos $50 \%$ do terreno disponível (BRASIL, 1985). Desta forma, não é suficiente julgar somente a área do terreno, também é preciso buscar a qualidade do espaço.

Outra característica que evidencia a noção existente do pátio escolar como espaço residual é que as atividades diversas de apoio ao processo pedagógico, entre elas as lúdicas, encontram-se dispersas no programa de atividades pedagógicas. O "brincar" deve fazer parte do processo educativo. A atividade lúdica possibilita que a criança experimente, explore, desenvolva sua vivência com o mundo concreto e subjetivo. No entanto, os pátios e as áreas livres das escolas têm sido reduzidos ou até mesmo eliminados e, quando existem, são geralmente pouco convidativos ou acumulam outras funções, como extensão do refeitório e da área de circulação.

Nos locais e situações de brincadeira, a criança é agente de seu próprio desenvolvimento, na medida em que atua selecionando as suas atividades e objetos, seus lugares preferidos e seus colegas; por outro lado, ela também é influenciada pelo ambiente sócio físico em que se encontra, o que pode facilitar e alterar seus comportamentos. Conforme Sanoff (1994), um lugar com aparência de abandono e descuido é repelido pelas crianças, ao mesmo tempo em que, se bem conservado, contribui de forma positiva para o processo de sua apropriação. A forma de a criança agir, por sua vez, também modifica o ambiente.

Segundo Gonçalves e Flores (2011), uma boa arquitetura de pátio escolar deve atender as necessidades das crianças de: (a) estabelecer o contato social para permitir 0 desenvolvimento das habilidades de comunicação que não são permitidas em sala de aula, como o diálogo espontâneo ou o namoro, (b) brincar e jogar, atividades lúdicas que podem acontecer de maneira espontânea, além de desenvolver a capacidade do trabalho em equipe; (c) desenvolver a motricidade e os sentidos, que são atividades que permitem à criança conhecer-se melhor e ter um controle maior sobre o seu corpo, aumentando a 
autoestima e a confiança em si mesma; (d) complementar as funções pedagógicas quando o espaço livre serve como exemplo ou complemento do conteúdo trabalhado em sala de aula e (e) aproximar-se do meio ambiente e da própria educação ambiental.

Assim, como espaço de aprendizagem, o pátio ideal deve possuir mais que quadras e parques infantis, que são equipamentos encontrados em outras edificações não escolares. Segundo Macedo (2011), as decorações e murais comumente encontradas se mostram vazias diante o aluno sonhador e cheio de imaginação. Como conceito principal, o pátio precisa servir de local complementar ao aprendizado, proporcionando transição entre espaços abertos ao ar livre e cobertos, oferecendo possibilidades diversas de usos e apropriações. Fedrizzi (1999) defende a necessidade de que o pátio da escola possua certos elementos e ofereça oportunidades e facilidades. Seriam eles: demonstrar receber cuidado, possibilitar a aprendizagem, dar oportunidades para brincar, oferecer segurança, possuir uma horta e pomar, ter a presença de vegetação, canchas para esportes, recantos ou esconderijos e abrigo contra intempéries.

A setorização e organização não podem ser rigorosas, permitindo que a criança possa controlar e se apropriar desse ambiente. Entende-se que, quanto melhor for a qualidade do ambiente físico, maior será a qualidade de vida do usuário, tanto no aspecto psicológico quanto no físico, pois, se o ambiente não estiver adequado às necessidades do usuário, pode produzir consequências negativas a este (AZEVEDO; BASTOS, 2002; ELALI; PINHEIRO, 2003).

Rapoport (1984) defende a ideia de que a arquitetura possibilita prover ambientes para determinadas atividades, podendo, desta forma, lembrar aos usuários quais são essas atividades, permitindo denotar força, status ou privacidade, comunicar informações, estabelecer identidade individual ou de um grupo e codificar sistemas de valores. É possível, por meio do planejamento do ambiente construído, facilitar certos tipos de comportamento. Ainda, Kowaltowski (1989) reitera que muitos estudos constataram que, quando o espaço não está apropriado à satisfação e necessidades do usuário, principalmente nos aspectos de condições de acústica, higiene e densidade espacial, podem surgir tensão, angústia e estresse.

Neste pensamento, Rioli (2016) afirma que, para que o pátio obtenha êxito na sua função e uso, a interação com o ambiente deve possibilitar a construção de habilidades físicas, intelectuais e emocionais específicas à cada faixa etária. Conforme a autora, deve-se considerar também as características das crianças (idade e gênero) e seu reflexo no uso do espaço.

Desse modo, quanto melhor for a qualidade do ambiente físico, maior será a qualidade de vida do usuário, tanto no aspecto psicológico quanto físico, pois se o ambiente não estiver adequado às necessidades deste usuário, pode produzir consequências negativas a este (AZEVEDO \& BASTOS, 2002; ELALI \& PINHEIRO, 2003; LIMA, 1995).

No que tange às técnicas subjetivas elencadas para o desenvolvimento desta pesquisa, Rheingantz et al. (2009), no livro Observando a Qualidade do Lugar, aborda o mapa cognitivo ou mapa mental, elaborado por Kevin Lynch nos anos 50. Este instrumento consiste na elaboração de desenhos ou relatos de memórias representativas das ideias que uma pessoa tem de um determinado ambiente, podendo ser preenchido através de desenhos ou escrita.

Deste modo, o mapa cognitivo se torna uma importante ferramenta para auxiliar na identificação de quais espaços e características da escola analisada que expressam valores visuais para seus usuários, demonstrando a visão que as crianças e jovens têm da mesma.

Os autores Hart e Sheenam (1986) destacam a importância de ouvir as crianças para entender suas necessidades, sendo insuficiente apenas observá-las. Nesta ótica, o poema dos desejos, instrumento de pesquisa desenvolvido por Henry Sanoff (2001), caracteriza-se 


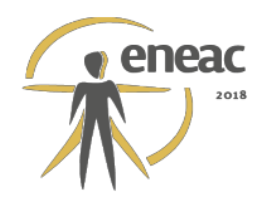

pela expressão gráfica dos usuários, através de desenhos ou pela escrita, de suas relações emocionais e expectativas sobre determinado ambiente. Tem como ponto de partida a sentença previamente proposta "Eu gostaria que o (edifício/ ambiente)...", tratando-se de um instrumento não estruturado e de livre expressão (RHEINGANTZ et al., 2009).

\section{INSTRUMENTOS E OBJETO DE ANÁLISE}

\subsection{Instrumentos de pesquisa}

Para que os objetivos inicialmente propostos na pesquisa sobre pátios escolares fossem obtidos, foram eleitos diferentes instrumentos de pesquisa com finalidade de compreender a organização espacial existente, as preferências dos usuários e as atividades realizadas nos diferentes espaços, entre outras informações relevantes.

Deste modo, na primeira aproximação foram identificadas sete escolas públicas que ofereciam Ensino Fundamental na cidade de Palmitinho/RS. Após visitação e observação destas escolas, elegeu-se o Instituto Estadual de Educação 22 de Maio para compor este estudo. A instituição elencada para a realização do estudo de caso apresentou um maior número de atividades no pátio, bem como maior número de alunos na instituição, quando comparada as demais instituições de ensino identificadas na ocasião.

Posteriormente, foi aplicada a combinação de diferentes instrumentos metodológicos, a partir da observação do comportamento e impressões sobre o ambiente através dos instrumentos mapa cognitivo e "poema dos desejos".

O mapa cognitivo e o "poema dos desejos" foram elaborados em folhas de tamanho A4, contendo cabeçalho com identificação do projeto de pesquisa, local para identificação da turma e nome do respondente, itens sem obrigatoriedade de preenchimento, e mantendo a maior superfície em branco possível na folha para que fosse desenvolvido o desenho/texto por parte de cada criança.

A aplicação destes instrumentos de análise se deu com $20 \%$ dos estudantes do Ensino Fundamental ( $1^{\circ}$ a $9^{\circ}$ ano), previamente selecionados pelos professores responsáveis das turmas, tendo em vista a necessidade do preenchimento do termo de participação do aluno pelos pais ou responsáveis, num total de 80 participantes, com idade entre 6 e 14 anos. 0 termo de consentimento foi enviado para os pais dos alunos selecionados. Ressalta-se que se pretendia realizar a aplicação dos instrumentos com um número maior de alunos do que resultou, mas isto se tornou inviável devido à necessidade de assinatura do termo de consentimento, conforme relatado.

Referente à aplicação das técnicas, estas atividades ocorreram em espaço disponibilizado pela instituição de ensino, durante o período das aulas, sendo que durante este os alunos foram liberados a partir do consentimento dos professores. A conversação inicial deu-se com a apresentação do pesquisador e uma conversa descontraída sobre a aula em que estavam quando da liberação. Posteriormente, explicou-se o instrumento do Mapa cognitivo, deixando os alunos com um tempo livre para realização da atividade. Em um segundo momento, a atividade prosseguiu com a aplicação do Poema dos Desejos, vislumbrando um maior entusiasmo dos alunos, que exploraram sua imaginação.

Houve uma boa interação entre pesquisadores e professores da instituição em estudo, havendo uma colaboração destes quando do levantamento de campo e da aplicação dos instrumentos com os alunos. 


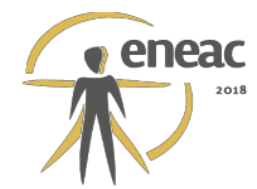

\subsection{Apresentação do local de estudo}

O Instituto Estadual de Educação 22 de Maio está localizado no centro da cidade de Palmitinho (Figura 01), em uma área de uso misto e próxima ao acesso pela RSC - 472. Foi inaugurado em 1954 e oferece ensino a 717 alunos nas modalidades: Ensino Fundamental, Ensino Médio Politécnico, Curso Normal e Educação de Jovens e Adultos- EJA.

\section{Figura 01: Implantação geral do Instituto Estadual de Educação 22 de Maio e entorno.}

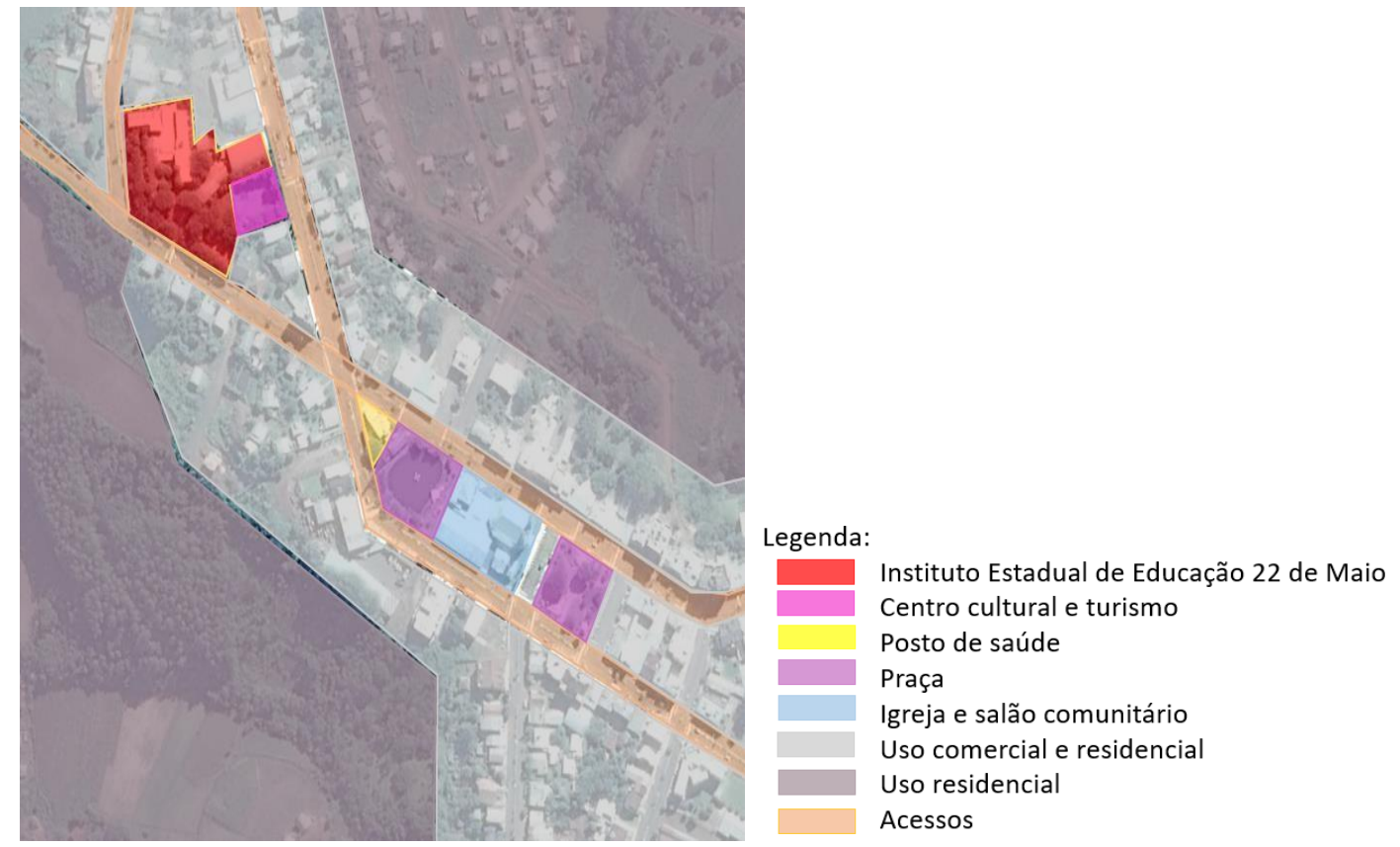

Fonte: Google Earth. Imagem adaptada pelas autoras, 2017

Evidencia-se a implantação da instituição de ensino em terreno com 9.030,00 $\mathrm{m}^{2}$, sendo a área construída de $3.540,00 \mathrm{~m}^{2}$. A área livre da escola é formada por um conjunto de pátios descobertos bem como playground e campo gramado. Ao observar a implantação da escola no lote, o pátio foi subdividido em três, sendo o pátio de acesso principal demarcado como pátio 01 , para o pátio 02 foi definida a grande área livre arborizada e campo de futebol e para o pátio 03 foi demarcado o espaço em meio às edificações onde está localizado o Playground (Figura 02). 


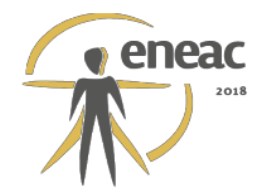

Figura 02: Planta com divisão dos pátios da Escola 22 de Maio

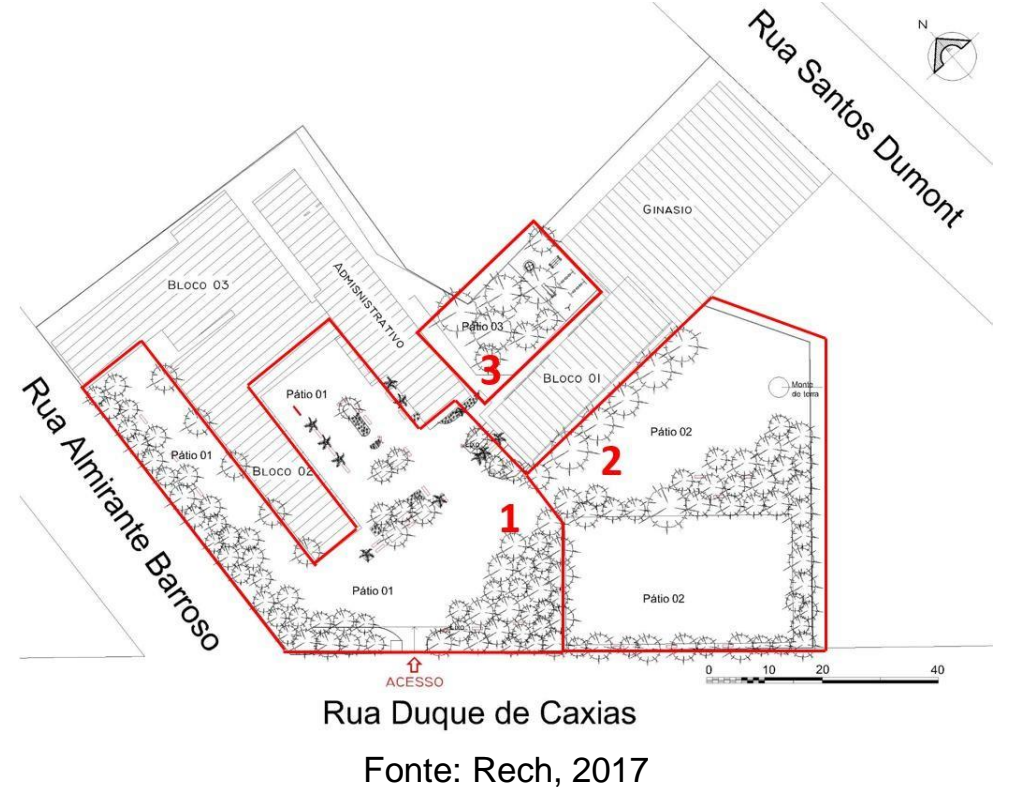

\section{SÍNTESE DOS RESULTADOS}

Após a seleção da escola para fins de observação e análise, a concessão de autorização do estudo da mesma por parte da direção e o recolhimento das assinaturas dos participantes dos termos de livre consentimento, documento exigido por lei para pesquisas envolvendo pessoas, foi iniciado o processo de levantamento do estudo de caso.

A primeira etapa de levantamento deu-se com a realização das visitas exploratórias e de leitura espacial e, posteriormente, com a aplicação do mapa comportamental e a elaboração do mapa cognitivo e do "poema dos desejos", sendo os resultados dos mesmos apresentados na sequência. Ressalta-se que a participação dos alunos, quando da aplicação dos instrumentos mapa cognitivo e poema dos desejos, foi consentida previamente pelos pais dos mesmos, a partir da assinatura do termo livre de consentimento. Verificou-se, quando da aplicação dos instrumentos, uma grande curiosidade por parte dos alunos participantes ou não da investigação, que se mostraram solícitos a colaborar e desenvolver as atividades propostas pelos pesquisadores.

Nesta perspectiva, tendo em vista que o mapa cognitivo e o poema dos desejos constituemse em ferramentas não estruturadas, as respostas obtidas são, em muitos casos, subjetivas, o que torna mais complexo o processo de tabulação dos resultados.

Em uma primeira etapa da análise, os resultados, tanto do mapa cognitivo como do poema dos desejos, foram separados por turmas. Uma vez que $20 \%$ dos alunos, entre $1^{\circ}$ a $9^{\circ}$ ano participaram da aplicação dos instrumentos, a separação dos mesmos se deu em duas categorias: de $1^{\circ}$ ao $5^{\circ}$ ano, que correspondem aos anos iniciais e de $6^{\circ}$ ao $9^{\circ}$ ano, anos finais do ensino fundamental. Em seguida, à categorização dos elementos gráficos conforme a recorrência dos desenhos/textos.

Deste modo, a fim de facilitar o ordenamento dos resultados, optou-se pela categorização das respostas em grupos, a saber: (a) ambiente físico/infraestrutura (espaços internos, espaços externos, ginásio, campo de futebol...), (b) elementos concretos (brinquedos...) (c) elementos afetivos/ lúdicos e atividades (relação entre alunos, harmonia, brincadeiras, música...), (d) elementos da natureza (água, animais, árvores e plantas...). Esta divisão foi feita de modo que, a partir da tabulação dos resultados, fossem originados gráficos que 


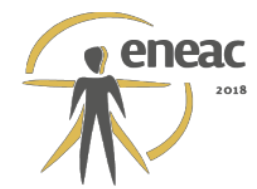

facilitassem a leitura e a análise, traduzindo os elementos mais significativos na cognição dos usuários.

A partir deste entendimento, na análise com os alunos de $1^{\circ}$ a $5^{\circ}$ ano 0 aspecto infraestrutura foi fortemente evidenciado, conforme o Gráfico 01 . Os mesmos abordaram os aspectos físicos da escola como edificação institucional, ginásio e o pátio escolar, este último visto como um espaço para brincadeiras, com a presença de algumas árvores, canteiros e bancos (Figuras 03 e 04).

\section{Gráfico 01: Tabulação dos resultados do mapa cognitivo dos alunos entre $1^{\circ}$ a $5^{\circ}$ ano.}
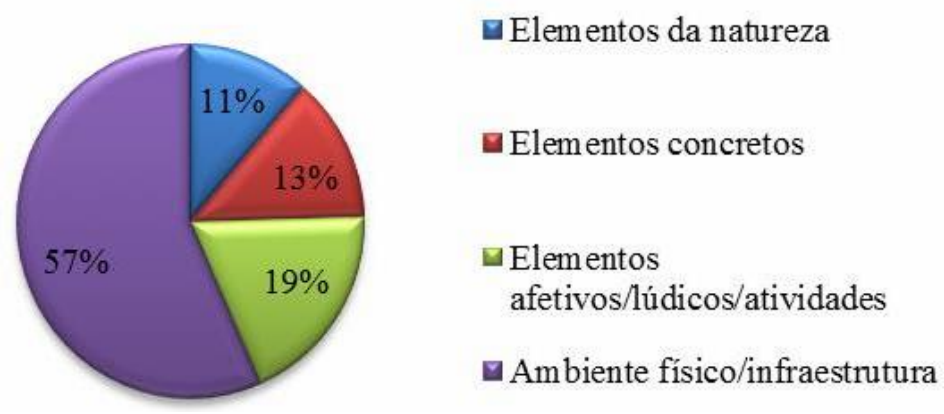

Fonte: Dados da pesquisa, 2016.

Figuras 03 e 04: Respostas obtidas quando da aplicação do instrumento com alunos de $1^{\circ}$ a $5^{\circ}$ ano.
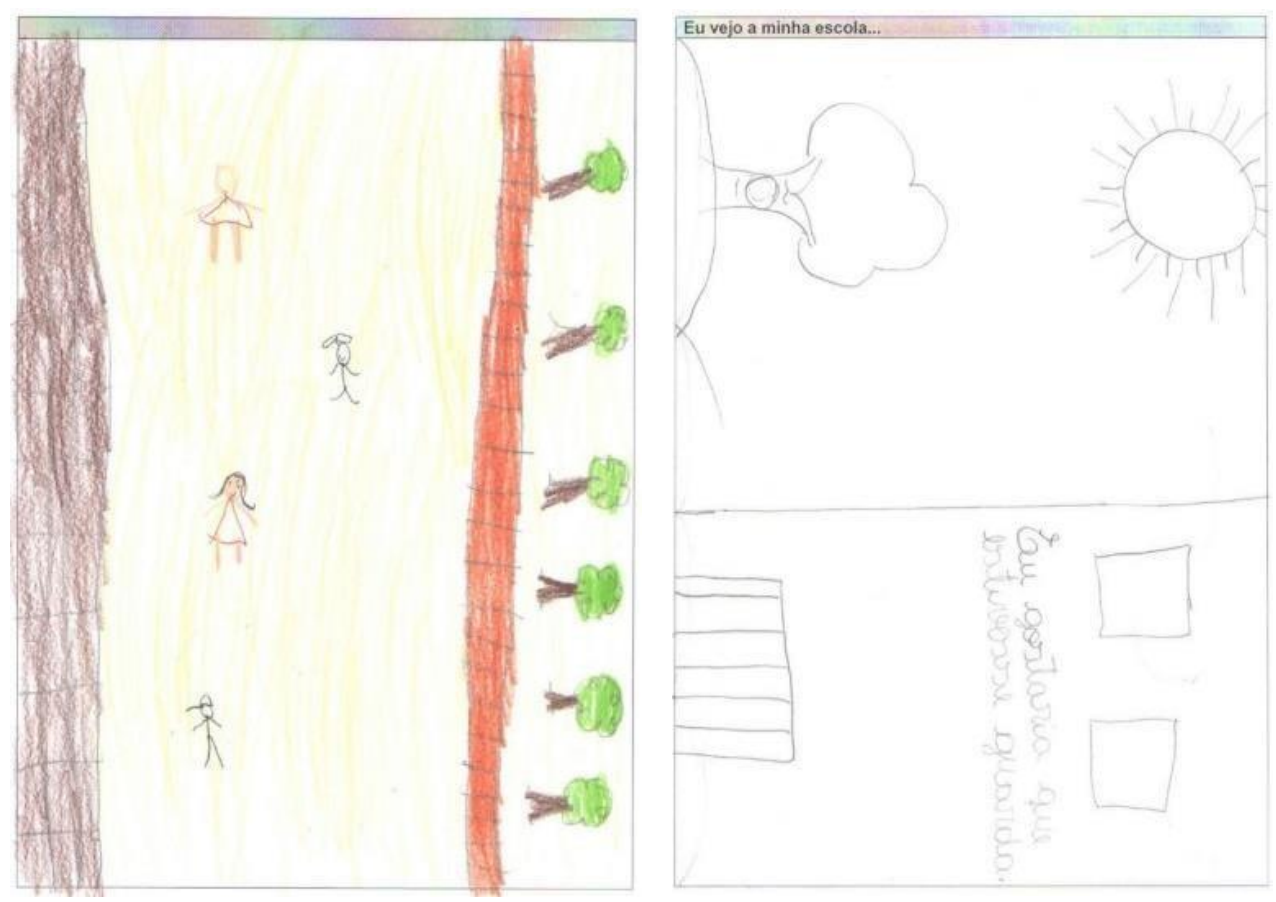

Fonte: Dados da pesquisa, 2016.

Os alunos do $6^{\circ}$ a $9^{\circ}$ ano não mantiveram o foco no pátio da escola e utilizaram a ficha do mapa cognitivo para criticar alguns aspectos da escola com os quais se demonstraram insatisfeitos. De um modo geral, pode-se dizer que muitos alunos evidenciaram a questão 


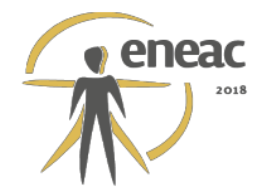

do pátio como sendo sujo e mal cuidado, mas reconheceram que para melhorar este aspecto é necessária uma mudança de atitude que deveria partir dos mesmos.

\section{Gráfico 02: Tabulação dos resultados do mapa cognitivo dos alunos entre $6^{\circ}$ a $9^{\circ}$ ano.}

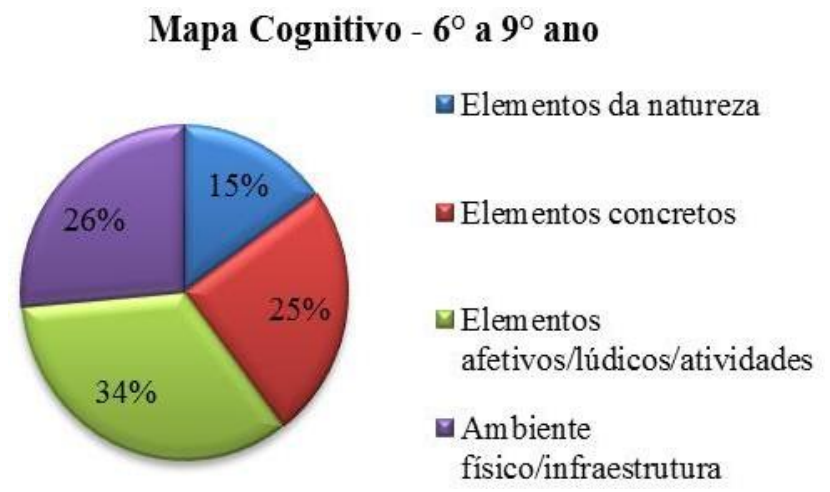

Fonte: Dados da pesquisa, 2016.

Referente ao instrumento de "Poema dos desejos" com a questão "Eu gostaria que a minha escola..." observou-se que a maioria das respostas obtidas quando da investigação com alunos de $1^{\circ}$ a $5^{\circ}$ ano estão relacionadas a elementos concretos, como mobiliário e brinquedos para o playground (Figura 05), bem como bancos e lixeiras, que deveriam ser distribuídas pelo pátio de forma a proporcionar espaços de convivência e de aspecto limpo e agradável (Gráfico 03).

Figura 05: Resposta obtida quando da aplicação do Poema dos desejos com aluno de $4^{\circ}$ ano.

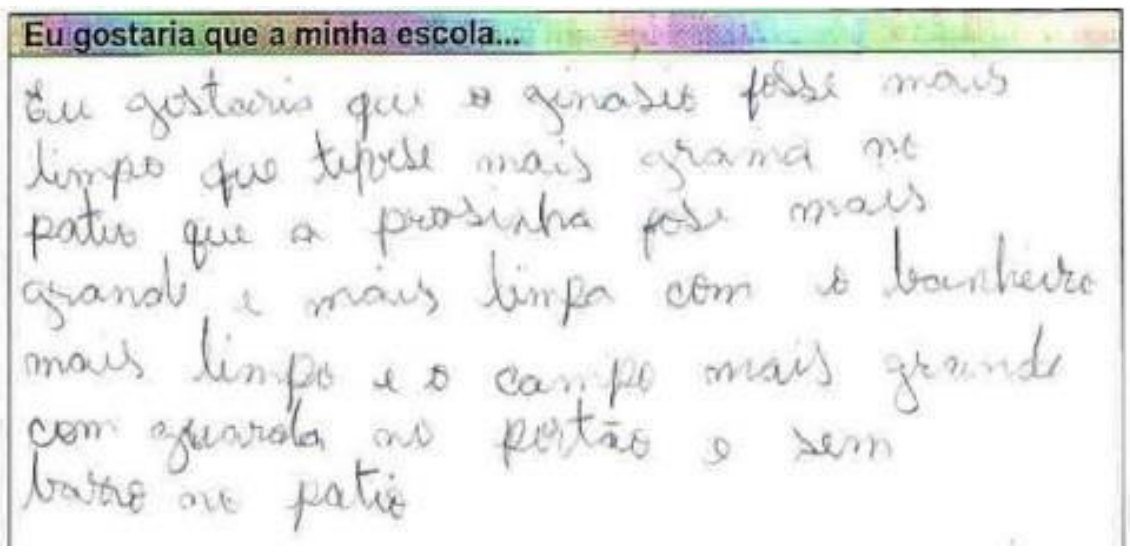

Fonte: Dados da pesquisa, 2016. 


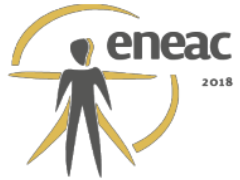

Gráfico 03: Tabulação dos resultados do Poema dos desejos com alunos entre $1^{\circ}$ a $5^{\circ}$ ano.

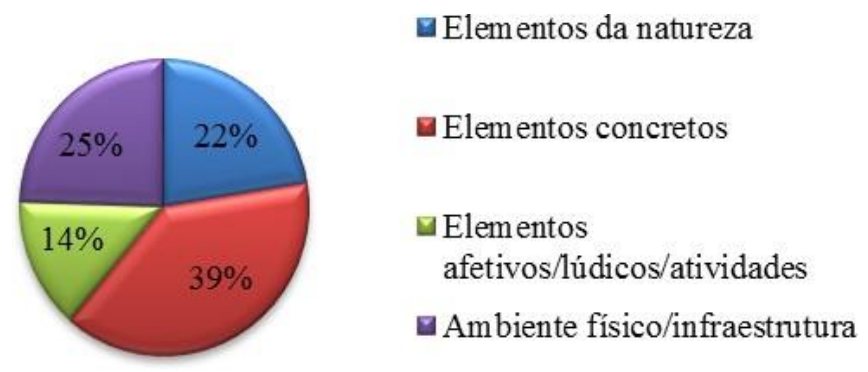

Fonte: Dados da pesquisa, 2016.

Em vista do exposto, reforça-se assim o ideal defendido por Elali (2003), que afirma que as áreas externas devem sempre estar equipadas com bancos para o descanso, bate-papo e pequenos agrupamentos. O mobiliário disponibilizado nos pátios, assim como suas disposições, são fatores importantes no uso do espaço.

No que tange ao levantamento realizado com os alunos de $6^{\circ}$ a $9^{\circ}$ ano, os maiores anseios foram relacionados a questões de elementos afetivos e atividades (Gráfico 04), mas estas questões não se voltaram para o pátio e sim para conflitos pessoais e reclamações sobre a edificação (Figura 06). Ressalta-se que, nas questões de infraestrutura, os alunos reforçaram a necessidade de reformas na cobertura do ginásio e melhorias no gramado do campo, bastante danificado.

\section{Gráfico 04: Tabulação dos resultados do Poema dos desejos com alunos entre $6^{\circ}$ a $9^{\circ}$ ano.}

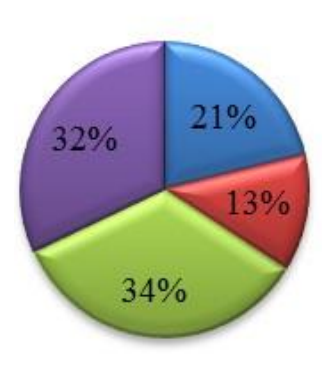

\author{
$\square$ Elementos da natureza \\ Elementos concretos \\ Elementos \\ afetivos/lúdicos/atividades \\ $\square$ Ambiente \\ físico/infraestrutura
}

Fonte: Dados da pesquisa, 2016.

Figura 06: Resposta obtida quando da aplicação do Poema dos desejos com aluno de $6^{\circ}$ ano.

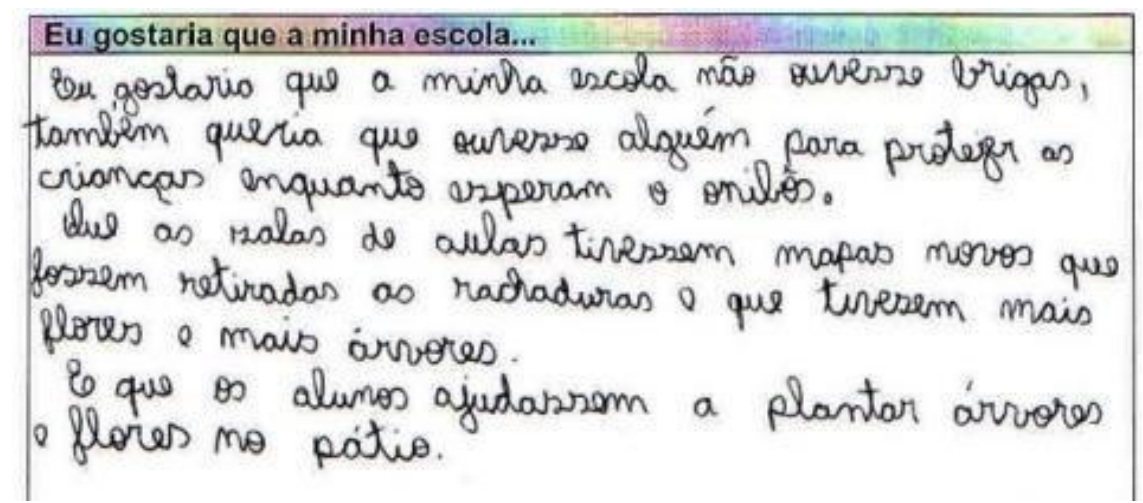

Fonte: Dados da pesquisa, 2016. 


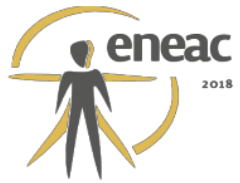

Assim, fica constatada a importância de ouvir as crianças usuárias dos ambientes, quando possível, para perceber o quanto são capazes de emitirem críticas e identificarem caracteristicas do pátio que facilitam a apropriação por parte dos usuários expressando suas necessidades e sugestões criativas quanto à melhoria do ambiente construído.

\section{CONSIDERAÇÕES FINAIS}

Pensar sobre os espaços de brincadeira e sua importância para o crescimento saudável das crianças é essencial para que se construam locais adequados às necessidades infantis. Nos pátios escolares, o processo de interação entre as crianças é bastante interessante, pois assume características distintas da sala de aula, possibilitando aos alunos relacionarem-se entre si. Desta forma, o levantamento realizado no Instituto Estadual de Educação 22 de Maio de ensino público fundamental confirma a importância da participação do usuário para a obtenção de espaços arquitetônicos de qualidade.

Assim, a análise das percepções dos usuários é extremamente importante na descoberta de aspectos que somente os mesmos podem perceber, tendo em vista que estes podem não ser significativos para os pesquisadores/observadores, mas que são marcantes e repletos de significados para quem experiencia aquele espaço no cotidiano. Da mesma forma, o pesquisador/observador contribui ao interagir com o espaço e o usuário, apontando aspectos negativos que passam despercebidos por quem está acostumado com tal espaço.

Neste contexto, a experiência obtida na pesquisa mostra que a avaliação pós-ocupação não se caracteriza apenas por uma avaliação técnica, mas sim representa uma investigação que também deve considerar a subjetividade e a expectativa dos usuários, sendo fundamental para a formulação do escopo de uma possível intervenção.

Assim, buscando contribuir para o entendimento do uso e apropriação dos pátios escolares pelos alunos, sugerem-se futuras pesquisa nas quais seja observado um maior número de pátios escolares, incorporando também os demais espaços do ambiente escolar.

\section{REFERÊNCIAS BIBLIOGRÁFICAS}

AZEVEDO, G. A. N.; BASTOS, L. E. Qualidade de vida nas escolas: produção de uma arquitetura fundamentada na interação usuário-ambiente. In: DEL RIO, V.; DUARTE, C. R.; RHEINGANTZ, P. A. (Orgs.), Projeto do lugar: colaboração entre psicologia, arquitetura e urbanismo (pp. 153-160). Rio de Janeiro: ContraCapa/PROARQ. 2002.

AZEVEDO, G. A. N.; RHEINGANTZ, P. A.; TÂNGARI, V. R. (Orgs). O lugar do pátio escolar no sistema de espaços livres: uso, forma e apropriação. Rio de Janeiro, UFRJ/FAU/PROARQ, 2011. 203 p. (Coleção PROARQ)

BRASIL, Ministério da Educação e da Cultura. Secretaria Geral. Centro de Desenvolvimento e Apoio Técnico à Educação (CEDATE). Manual para construções escolares. Brasília: MEC/SEF, 1985.

ELALI, G. A. O ambiente da escola - o ambiente na escola: uma discussão sobre a relação escola-natureza em educação infantil. Estudos de Psicologia, 8 (2), 2003, pp. 309-319.

ELALI, G. A.; PINHEIRO, J. Q. Edificando espaços, enxergando comportamentos. In: MARQUES, S.; LARA, F. (Orgs.), Projetar: desafíos e conquistas da pesquisa e do ensino de projeto. Rio de Janeiro: EVC. 2003, pp. 130-144.

FEDRIZZI, B. Paisagismo no pátio escolar. Porto Alegre: Editora da Universidade Federal do Rio Grande do Sul. 1999. 


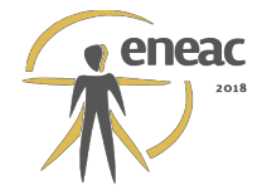

FEDRIZZI, B. A Organização Espacial em Pátios Escolares Grandes e Pequenos, In DEL RIO, V.; DUARTE, C.; RHEINGANTZ, P. A. (Orgs). Projeto do Lugar: Colaboração entre Psicologia, Arquitetura e Urbanismo. Rio de Janeiro: ContraCapa/PROARQ, pp 221-229, 2002.

GONÇALVES, F. M.; FLORES, L. R. Espaços livres em escolas: questões para debate. In: AZEVEDO, G. A. N.; RHEINGANTZ, P. A.; TÂNGARI, V. R. (Org.). O lugar do pátio escolar no sistema de espaços livres: uso, forma e apropriação. Rio de Janeiro, UFRJ/FAU/PROARQ. v.1, p.2333, 2011.

HART, C. \& SHEENAN, R. Preschoolers' play behavior in outdoor environments: Effects of traditional and contemporary playgrounds. American Educational Research Journal, 1986.

KOWALTOWSKI, D. K. Arquitetura escolar. O projeto do ambiente de ensino. São Paulo, Oficina de Textos, 2011.

KOWALTOWSKI, D. C. C. K. Arquitetura e humanização. Projeto, 126, 129-132. 1989.

LIMA, M. W. S. Arquitetura e educação. São Paulo: Nobel. 1995.

MACEDO, S. S.. Prefácio. In: AZEVEDO, G. A. N.; RHEINGANTZ, P. A.; TÂNGARI, V. R. (organizadores). O lugar do pátio escolar no sistema de espaços livres: uso, forma e apropriação. Rio de Janeiro, UFRJ/FAU/PROARQ, 2011. 203 p. (Coleção PROARQ).

NORBERG-SCHULZ, C.; DIGERUD, J. G. (colaboração). Louis I. Kahn, Idea e imagen. Madrid: Xarait editiones, 107 p., il. 1981.

RAPOPORT, A. Origens culturais da arquitetura. In J. Snyder \& A. J. Catanese (Orgs), Introdução à Arquitetura (pp. 26-42). Rio de Janeiro: Campus. 1984.

RECH, G.R.da F. Apropriação espacial em pátios escolares de Ensino Fundamental Público em Palmitinho-RS. Florianopólis: Universidade Federal de Santa Catarina - Dissertação de Mestrado em Arquitetura, 2017. 229p.

RHEINGANTZ, P. A.; AZEVEDO, G.; BRASILEIRO, A.; ALCANTARA, D.; QUEIROZ, M. Observando a Qualidade do Lugar: procedimentos para a avaliação pós-ocupação. Rio de Janeiro: FAUUFRJ (Coleção PROARQ), 2009.

RIOLI, T.O. Pátio escolar coberto: a qualidade ambiental, estética e funcional em escolas de Educação Infantil. Dissertação (Mestrado), Universidade Estadual Paulista. Faculdade de Arquitetura, Artes e Comunicação, Bauru, 2016.

SANOFF, H. School design. New York: John Willey and Sons, 1994.

SANOFF, H.. School Building Assessment Methods. Washington: National Clearinghouse for Educational $\quad$ Facilities, 2001. Disponível em http://www4.ncsu.edu/ sanoff/schooldesign/schoolassess.pdf acesso em jun./2016.

TAVARES FILHO, A. C. Reflexões sobre a Noção de Tipo Morfológico e o Programa Arquitetônico: Os Casos das Escolas Municipais Estados Unidos e República Argentina. Dissertação (Mestrado), Programa de Pós-graduação em Arquitetura. Universidade Federal do Rio de Janeiro, 2005. 